\title{
Modeling Road Safety in Car-Dependent Cities: Case of Jeddah City, Saudi Arabia
}

\author{
Mohammed Aljoufie *(D) and Alok Tiwari (D)
}

check for

updates

Citation: Aljoufie, M.; Tiwari, A. Modeling Road Safety in CarDependent Cities: Case of Jeddah City, Saudi Arabia. Sustainability 2021, 13, 1816. https://doi.org/10.3390/ su13041816

Academic Editor: Elżbieta Macioszek Received: 19 January 2021

Accepted: 4 February 2021

Published: 8 February 202

Publisher's Note: MDPI stays neutral with regard to jurisdictional claims in published maps and institutional affiliations.

Copyright: (c) 2021 by the authors. Licensee MDPI, Basel, Switzerland. This article is an open access article distributed under the terms and conditions of the Creative Commons Attribution (CC BY) license (https:// creativecommons.org/licenses/by/ $4.0 /)$.
Department of Urban and Regional Planning, Faculty of Architecture and Planning, King Abdulaziz University, Jeddah 21589, Saudi Arabia; atwari@kau.edu.sa

* Correspondence: maljufie@kau.edu.sa

\begin{abstract}
Investigating the connections between pedestrian crashes and various urban variables is critical to ameliorate the prediction of pedestrian fatalities, formulate advisories for the stakeholders, and provide an evidence base for policy change to mitigate the occurrence and intensity of pedestrian fatalities. In this paper, we aim to explore the geographically varying association between the pedestrian fatalities and other associated factors of an urban environment in Jeddah city, which is a cardependent city in Saudi Arabia. At first, Global Moran's I and Local Indicators of Spatial Association (LISA) were applied to visualize the clustering of pedestrian fatalities in the various districts of Jeddah. Subsequently, we developed Poisson regression models based on their geographically weighted indicators. Both the global and geographically weighted regression models attempt to assess the association between the pedestrian fatalities and the geographically relevant land use and transport infrastructure factors. The results indicate that geographically weighted Poisson regression (GWPR) performed better than the global Poisson counterparts. It is also revealed that the existing transportation infrastructure in Jeddah was significantly associated with the higher pedestrian fatalities. The results have shown that the proposed model in this study can inform transport policies in Jeddah in prioritizing more safety measures for the pedestrians, including expanding pedestrians infrastructure, and cautious monitoring of pedestrian footpaths. It can facilitate the analysis and improvement of road safety for pedestrians in car-dependent cities.
\end{abstract}

Keywords: traffic safety; Jeddah; pedestrian fatality; geographically weighted regression (GWR)

\section{Introduction}

Traffic safety is obviously an issue of deep concern because as many as 1.35 million people die each year [1], and 20 to 50 million people encounter non-fatal injuries due to traffic-related crashes. In fact, traffic crashes has become a crucial public health crisis and a serious challenge for the professionals engaged in injury prevention [2,3]. A recent study has estimated that the traffic accidents will cost $\$ 1.8$ trillion to the global economy during 2015-2030 [4]. Most importantly, an increase in road fatalities hinders attainment of target 3.6 of the Sustainable Development Goals: reducing fatalities in road crashes by $50 \%$ by 2020 to ensure healthy lives and promote well-being for all at all ages [5]

The literature suggests that pedestrians are the most vulnerable in traffic mishaps; however, intensity of loss of lives is lower in high-income countries [6]. There are several reasons responsible for pedestrian's fatalities in a road crash including the design of roadways and pedestrian infrastructure $[7,8]$, speed of vehicles $[9,10]$, influence of alcohol on drivers or pedestrians $[11,12]$, volume of traffic $[13,14]$, insufficient visibility of pedestrians $[15,16]$, age of pedestrians $[17,18]$, safety measures in and around public transit $[19,20]$, land-use planning factors [21,22], and recent socio-technical changes such as emergence of autonomous vehicles [23] and relentless use of smartphones [24,25].

Designs of roadways and pedestrian pathways are understood to be the most responsible factor for collisions amid vehicles and pedestrians. According to Lakhotia et al. [19], 
usually, the grade-separated intersections are constructed by local bodies in order to ease congestion at the intersections. However, this type of intersection accelerates the speed of vehicles, and it subsequently increases distress for the pedestrians. Grade-separated intersections become more dangerous if a pedestrian wants to cross the road [26].

The latest socio-technical changes put the safety of pedestrians at stake; for instance, the development of autonomous vehicles such as self-driving cars have not been able to utterly respond to the concerns of pedestrians and drivers [23]. Apart from that, Nasar and Troyer [27] reported that the injuries (mostly non-fatal) among pedestrians in USA has increased in recent years because of using smartphones while walking. In an important experimental study, Simmons et al. [24] observed that using smartphones while crossing distracts pedestrians and reduces the rate of watching their left and right sides while crossing. Hence, the ubiquity of smartphones use is distracting both the drivers and pedestrians, which is endangering their health and life.

As a result, there are many studies that investigate factors responsible for road accidents. However, the significance of these factors may vary in the specific geographies and socioeconomic circumstances. In above context, there is a lack of studies that focus on the effective factors in a typical perspective.

Meanwhile, the recent Vision 2030 of the Kingdom of Saudi Arabia has given utmost importance to traffic safety [28]; the traffic safety scenario is not encouraging even in Saudi Arabia, where the number of deaths in road crashes has increased from 17.4 to 27.4 for every 100,000 people in the past few decades (Jamal et al., 2019; World Health Organization, 2018). On average, one hourly death and four injuries are recorded in the kingdom [28]. In addition, Ministry of Health hospitals record $80 \%$ deaths and $20 \%$ occupied beds because of road traffic accidents [29]. Studies in Saudi Arabia also established that with the fast development of road infrastructure and rise in the number of vehicles, road traffic accident is becoming a serious public health crisis that could not be overlooked [28]. This study presents a case study on the geographical heterogeneity of pedestrian fatalities in Jeddah city in which the traffic safety scenario is similar to other Saudi cities that are car dominated. Jeddah is a polycentric city with a limited modal share of pedestrian and public transportation trips. In 2017, the rate of pedestrian fatality in the city was 81 (per million population), which is comparatively higher than other global cities.

We argue that understanding the locational heterogeneity of road injuries and how they are distributed among the various micro geographical areas is vital for policy making. Hence, we developed a mixed method model to inform transport policymakers. Secondary data on pedestrian fatality locations were obtained from Jeddah traffic police, and the population densities were obtained from the Saudi census, while other primary data related to urban environment were collected through field survey. We used Moran's I and Local Indicators of Spatial Association (LISA) to find out spatial clustering of pedestrian fatalities in Jeddah, and then Exploratory Factor Analysis (EFA) with Kaiser criterionbased Scree plot was used to obtain two retainable factors, after the removal of variables with low community value and low eigenvalue. Finally, a Global and Geographically Weighted Regression (GWR) model with Poisson distribution was proposed and compared to inform policies.

In brief, this study attempts to explore the geographically varying association between the pedestrian fatalities in Jeddah and other associated factors of an urban environment. We believe that this study will offer a solid base for transport policymakers in making evidence-based policies. The rest paper is structured in five more sections. Section 2 highlights the salient characteristics of the study area, Section 3 gives overview on the mechanism in which the data for this study is assembled, Section 4 provides explanation on the methods used in this study, Section 5 presents the results, and Section 6 comprises the discussion and limitations of this study. Finally, Section 7 offers the concluding remarks. 


\section{Case Study City-Jeddah}

Located at the coast of Red Sea, Jeddah is the second largest city of Saudi Arabia. It had an estimated population of 3.5 million people in 2020, with a residential density of 2500 person per square kilometres (Figure 1). The city is highly car-dependent as an outcome of the economic prosperity achieved due to an oil boom, low-density urban expansion at the outer areas of the city, and the limited availability of public transportation, among other reasons. Additionally, the hot humid climate and lack of thermal comfort $[30,31]$ deters people from walking and cycling in Jeddah.

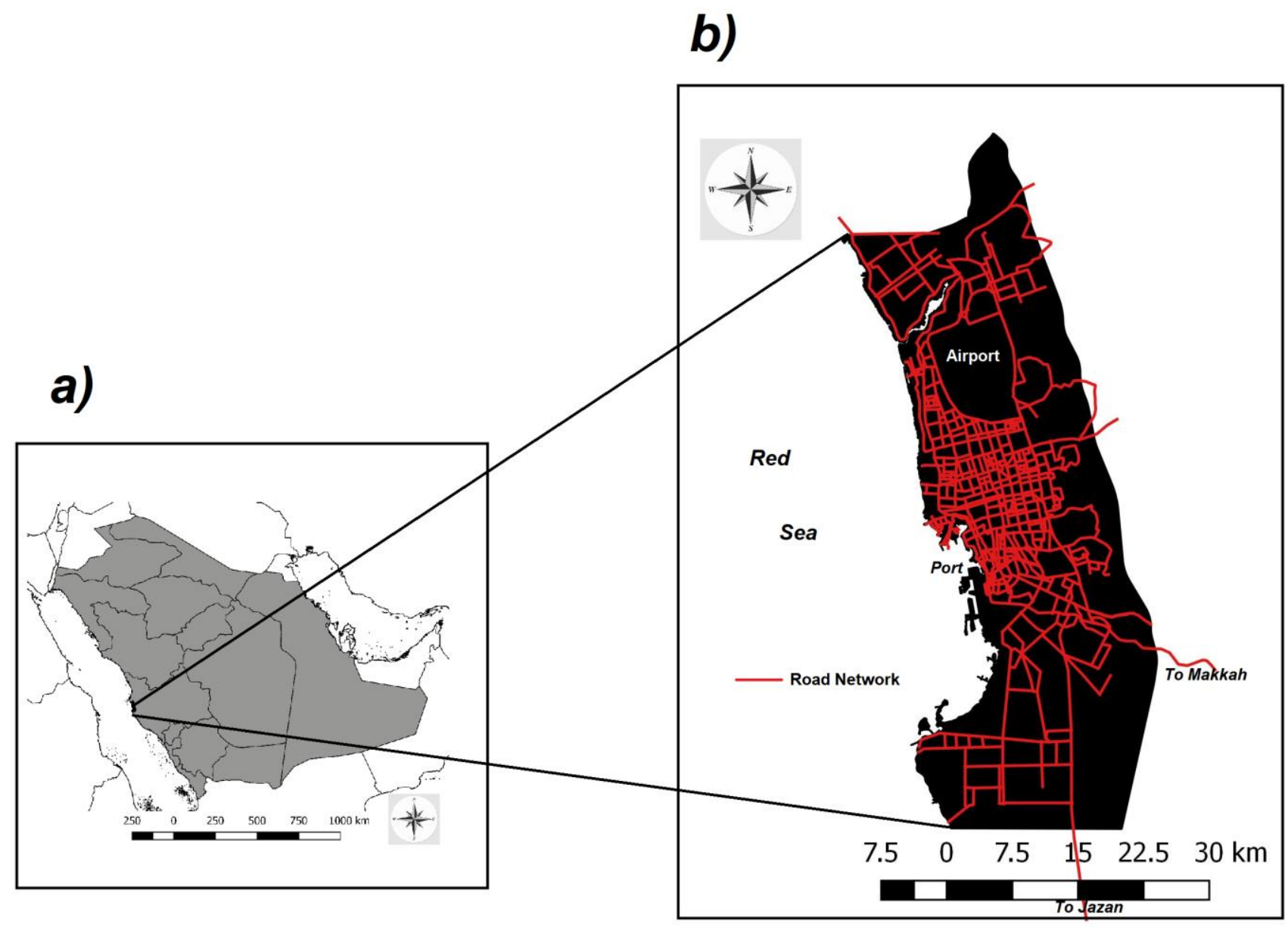

Figure 1. Location map of Jeddah.

A remarkable expansion in Jeddah's road infrastructure was witnessed over the past few decades. The total length of roads was only $101 \mathrm{~km}$ in 1964, which has expanded nearly 10 -fold after 50 years. A major part of the current road network was built in the city during the 1970s, which is known as the golden age for roads [32]. The road network in Jeddah was designed all the way through a linear grid pattern because the city was contracted between the red sea and mountains from the two sides [33,34].

Additionally, the city has witnessed drastic change in modal share because of irregular spatial expansion that was not serviced with matching road infrastructure. There was a huge decline in non-car travel mode share over four decades, and it shrank from $50 \%$ in 1970 to a low of $7 \%$ in 2007. Car trips were overshadowed with a modal share of $93 \%$ in 2007 which was only $50 \%$ in 1970 . On the contrary, the modal share of public transportation trips also fell from $19 \%$ in 1970 to $2.3 \%$ in 2007. 
Moreover, the non-motorized transport trips including pedestrians and cycling became negligible in the reported period. Public transportation in Jeddah did not match with rapid urbanisation and population growth. Approximately $98 \%$ of city residents use private vehicles for their transit needs [35]. Public transport in the city is confined within the inner part of the city and used by the low-income households and some expatriate workers. There is a common consensus among residents that the existing public transport in the city disregards their individual preferences. Car ownership in Jeddah is exceptionally high because of limited public transportation coverage. The traffic monitoring unit in Jeddah recorded the movement of 5.2 million vehicles in August 2019, while the number of daily trips were 167,000 with an average speed of $103 \mathrm{kmph}$ [36]. Although the city of Jeddah has plans to cover the city boundaries with a mass rapid transport system including metro trains and trams, and the Saudi Vision 2030 has strongly asserted the similar notion [37].

\section{Data}

The modal share of pedestrian trips is too limited in Jeddah city in comparison to other selected global cities (Table 1), it could be one of the reasons for a higher rate of pedestrian fatalities. We obtained data on pedestrian fatalities in Jeddah for the year 2016-2017 from Jeddah Traffic Police. Fatality rate for the reported year stays 81 on per million population.

Table 1. Pedestrian safety in selected cities.

\begin{tabular}{ccccccc}
\hline Pedestrian Safety & Units & Jeddah & Dubai & Delhi & Cairo & New York \\
\hline $\begin{array}{c}\text { Modal share of } \\
\text { pedestrian trips }\end{array}$ & $\%$ & 9 & 13 & 20 & 20 & 11 \\
\hline $\begin{array}{c}\text { Pedestrian fatalities } \\
\text { in reported year }\end{array}$ & Per million population & 81 & 0.59 & 46 & 84 & 98 \\
$(2017)$ & $(2019)$ & $(2010)$ & $(2019)$ \\
\hline
\end{tabular}

Several studies found land uses as the most dominating risk factor for traffic fatalities. The urban built environment is a product of land-use policies, and land-use decisions affects many concerns of the built environment including urban sprawl, air pollution, noise pollution, climate change, and traffic accidents [38,39]. Land-use types are apparently linked with the traffic crashes. For example, crashes are more frequent in the countryside rather than urban highway segments [40,41]. Ewing et al. [42] suggested population density as a significant factor in traffic crashes and reported that more dense areas count comparatively lower traffic fatalities. According to Golob and Recker [43], traffic volume rather than speed of vehicles was the key factor for the severity of crashes in southern California. Another study found that volume-to-capacity ratio $(v / c)$ was negatively associated with traffic crashes in the Detroit area [44]. Empirical evidence from a Croatian city hints that more people were hurt on urban intersections [45].

Hence, based on above appraisal, we selected multiple independent variables comprising land uses including population (residential) density, institutional density, hospital density, school density, commercial centre density; and transport infrastructure inclusive of road intersection density, road volume capacity ratio, road density, traffic signal density, and foot over bridge density (Table 2). 
Table 2. Variables used for pedestrian fatality modeling.

\begin{tabular}{ccc}
\hline Variable & Year & Source \\
\hline 1. Accident counts for pedestrians & 2017 & Jeddah Traffic Police \\
\hline Land uses & & \\
2. Population (Residential) density & 2010 & Census 2010 \\
3. Institutional density & 2019 & Field Survey \\
4. Hospital Density & 2019 & Field Survey \\
5. School Density & 2019 & Field Survey \\
6. Commercial centre density & 2019 & Field Survey \\
\hline Transport infrastructure & & \\
7. Road intersection density & 2019 & Field Survey \\
8. Road volume capacity ratio & 2019 & Field Survey \\
9. Road density & 2019 & Field Survey \\
10. Traffic signal density & 2019 & Field Survey \\
11. Foot over bridge density & 2019 & Field Survey \\
\hline
\end{tabular}

\section{Method}

We visualize Global Moran I and LISA for the outcome variable (pedestrian fatality counts in Jeddah) in GeoDa 1.14.0 environment, which is suitable software for the exploratory spatial data analysis (ESDA). Again, Exploratory Factor Analysis (EFA) was carried out to reduce dimensionally of variables in IntellectusStatistics. Finally, we used GWR 4.0.90 in combination with QGIS 3.0 to model and visualize the results of global and geographically weighted Poisson regressions.

\subsection{Dependent Variable}

We used pedestrian fatalities (count data) as dependent variable for the regression models, in each of the 113 districts of Jeddah. We derived the pedestrian fatalities by count points in polygon algorithm in the vector analysis toolbox of QGIS. We found that pedestrian fatalities range from 0 to 62 in the different districts of Jeddah in the year 2017.

Next, we applied EFA with the help of IntellectusStatistics [46] to obtain retainable factors from the independent variables. Then, the principal factor scores were calculated in MS-Excel and then processed in GWR 4.0.90.

\subsection{Independent Variable}

Grekousis [47] suggested using Principal Component Analysis (PCA) or any similar type of factor detection analysis to remove collinearity, dimension reduction of multivariate data, and to find latent variables. Hence, we deployed Exploratory Factor Analysis (EFA) to obtain retainable factors. In the first EFA, we found that "institutional density" (land uses) and "foot over bridge density" (transport infrastructure) have low communality $(<0.40)$ for which an addition factor might be explored, as the factor structure does not sufficiently define the data as recommended by Costello and Osborne [48].

Consequently, we ran a second and final EFA with remaining eight independent variables using Kaiser criterion [49] to figure out the number of factors to retain with oblimin rotation [50].

Next, we computed Pearson correlation to find the intercorrelations for each variable. All 8 variables secured at least one correlation coefficient $>0.30$ and seem fit for factor analysis [51]. The value of the correlation matrix was 0.0033 , indicating that there is no multicollinearity (as the value was $>0.00001$ ) in the data [52].

We use up a common practice of Kaiser's eigenvalue $>1$ to keep the factors $[53,54]$ and extracted 2 factors with had an eigenvalue more than one. Both factors together explained $60.16 \%$ of total variance in the data, where Factor 1 with eigenvalue 2.57 described $32.15 \%$ variance, and Factor 2 with eigenvalue 2.24 explained the remaining $28.01 \%$ of variance (Table 3). A scree plot (Figure 2) illustrates the number of significant factors with the Kaiser criterion. 
Table 3. Percentage of variances of obtained factors.

\begin{tabular}{cccc}
\hline & Eigenvalue & \% of Variance & Cumulative \% \\
\hline 1 & 2.57 & 32.15 & 32.15 \\
2 & 2.24 & 28.01 & 60.16 \\
\hline
\end{tabular}

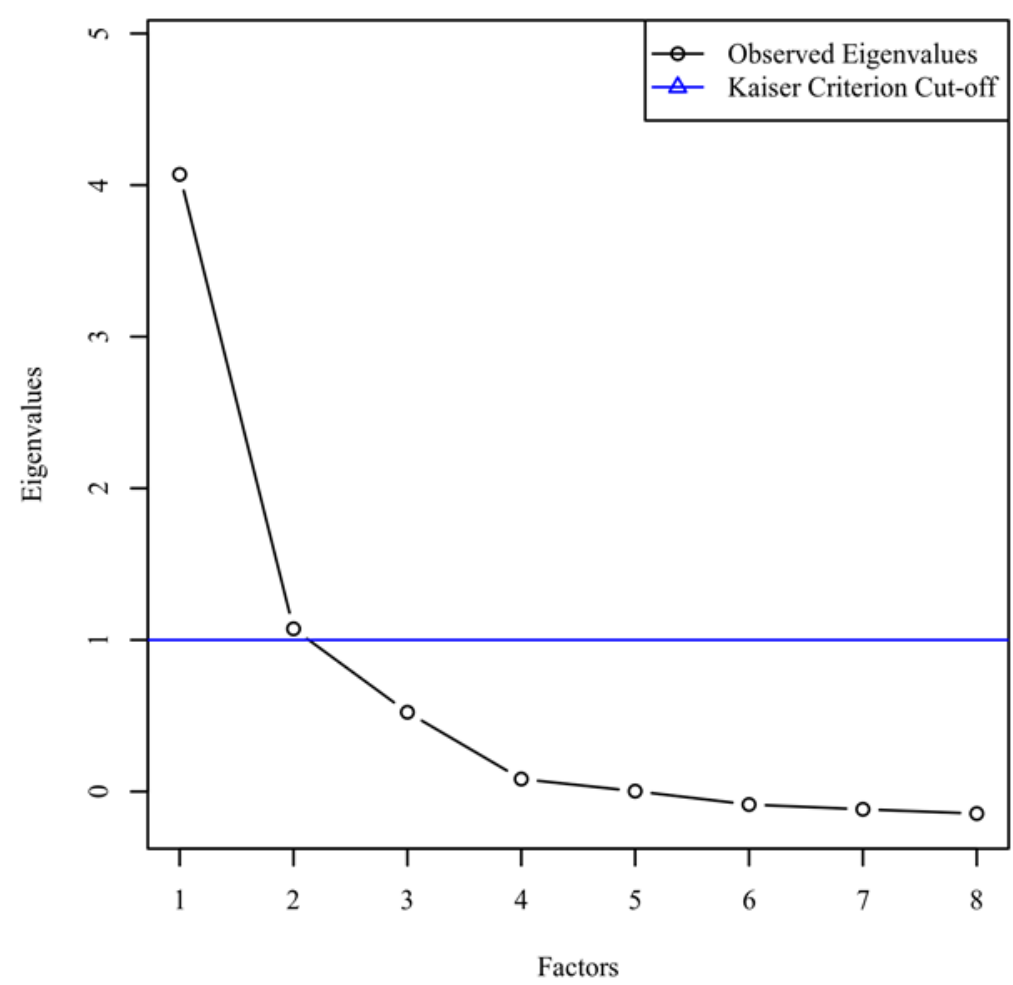

Figure 2. Screen plot with the Kaiser criterion.

We used Comrey and Lee [55] criterion (Table 4) to interpret factor loading that considers the absolute value of each loading. In fact, factor loading is the quantification of a variable with a factor given; in other words, factor loading is the correlation coefficient for the factor and variable. It helped researchers to make decision on the inclusion of a variable for a given factor. Based on the results of factor loadings from EFA (Table 5), "commercial center density" and "population (residential) density" had excellent loadings (value > 0.71) for Factor 1, while "school density" and "hospital density" had very good loading (value 0.63-0.71); other loadings were insignificant for this factor. For Factor 2, "road intersection density" and "road density" had excellent loadings (value > 0.71), "road volume capacity ratio" had very good loadings (value $0.63-0.71$ ), and "traffic signal density" had poor loadings (value $0.32-0.45$ ), while other loadings were insignificant for this factor.

Table 4. Factor loadings criterion by Comrey and Lee [55].

\begin{tabular}{cc}
\hline Value & Interpretation \\
\hline$>0.71$ & Excellent \\
$0.63-0.71$ & Very Good \\
$0.55-0.63$ & Good \\
$0.45-0.55$ & Fair \\
$0.32-0.45$ & Poor \\
\hline
\end{tabular}


Table 5. Factor Loadings from EFA.

\begin{tabular}{cccc}
\hline & \multicolumn{2}{c}{ Factor Loading } & \\
\cline { 2 - 3 } Variable & $\mathbf{1}$ & $\mathbf{2}$ & Communality \\
\hline $\begin{array}{c}\text { road intersection density } \\
\text { commercial center density }\end{array}$ & 0.90 & 0.85 & 0.70 \\
$\quad \begin{array}{c}\text { road density } \\
\text { school density }\end{array}$ & & & 0.70 \\
$\quad$ road volume capacity ratio & 0.67 & 0.95 & 0.88 \\
$\begin{array}{c}\text { population (residential) density } \\
\text { traffic signal density }\end{array}$ & 0.86 & 0.62 & 0.55 \\
$\quad$ hospital density & & & 0.50 \\
\hline Note: Factor loadings & & 0.64 & 0.87 \\
\hline
\end{tabular}

Note: Factor loadings $<0.32$ are suppressed.

There was no crossloading due to the absence of low communality $(<0.40)$ variables. This prompts that the factor structure explains the data well [48]. Crossloading happens while a lone variable has loading across several factors. The nonappearance of crossloading also prompts the factor structure to be straightforward and simpler to interpret. Each factor has a minimum of three significant loadings, making them consistent and strong [48].

In addition, PCA modifies the data from their basic dimensions to a new one to explain the data variations in a better way [47]; therefore, we used the scores from two factors as the independent variable in our model.

\subsection{Spatial Autocorrelation}

We applied spatial autocorrelation to explore the clustering of outcome variables that is pedestrian fatalities in the various districts of Jeddah. Spatial autocorrelation quantifies the magnitude of spatial dependency, correlation, or association between the observed value of a variable in a spatial unit and the observed value of a neighboring spatial unit of the same variable [47]. To measure global spatial autocorrelation, we used the Moran's I statistic [56], which is the most popular indicator of spatial association at the global level that evaluates the entire pattern of a spatial region [47,57].

In addition, we used LISA to map the location of spatial clusters and outliers [58]. LISA complements the shortcomings of global Moran's I.

\subsection{Regression Models}

As the outcome variable for this research was calculated for each district in Jeddah, we found Poisson regression right for modeling. Some earlier studies also used Poisson distribution to model traffic crashes [19,59]. We can express Poisson distribution as:

$$
\begin{gathered}
y_{i}=\operatorname{Poisson}\left(\lambda_{i}\right) \\
\log \left(\lambda_{i}\right)=\log \left(e_{i}\right)+\beta_{0}+\beta X_{i}
\end{gathered}
$$

where $y_{i}$ is the observed count of pedestrian fatalities, $\lambda_{i}$ is the expected fatality count (Figure 3), exposure is $e_{i}, \beta_{0}$ and $\beta$ are the coefficients, and $X_{i}$ is the independent variable.

Some earlier studies concluded that global regression alone is not sufficient to measure spatially clustered association; hence, the local counterpart of global regression should be used: geographically weighted regression (GWR) [19]. GWR is used to analyze spatially varying relationships and explore spatial heterogeneity [60]. GWR (for the Poisson distribution) could be expressed as the following:

$$
\log \left(\lambda_{\mathrm{i}}\right)=\log \left(\mathrm{e}_{\mathrm{i}}\right)+\beta_{0}\left(\mathrm{u}_{\mathrm{i}} \cdot \mathrm{v}_{\mathrm{i}}\right)+\beta\left(\mathrm{u}_{\mathrm{i}} \cdot \mathrm{v}_{\mathrm{i}}\right) \mathrm{X}_{\mathrm{i}}
$$

where $y_{i}$ are the observed count of pedestrian fatalities, $\lambda_{i}$ is the expected fatality count, exposure is ei, $\beta_{0}$ and $\beta$ are the coefficients, $X_{i}$ is the independent variable, and $u_{i}, v_{i}$ stands for the coordinates of the spatial unit i. 


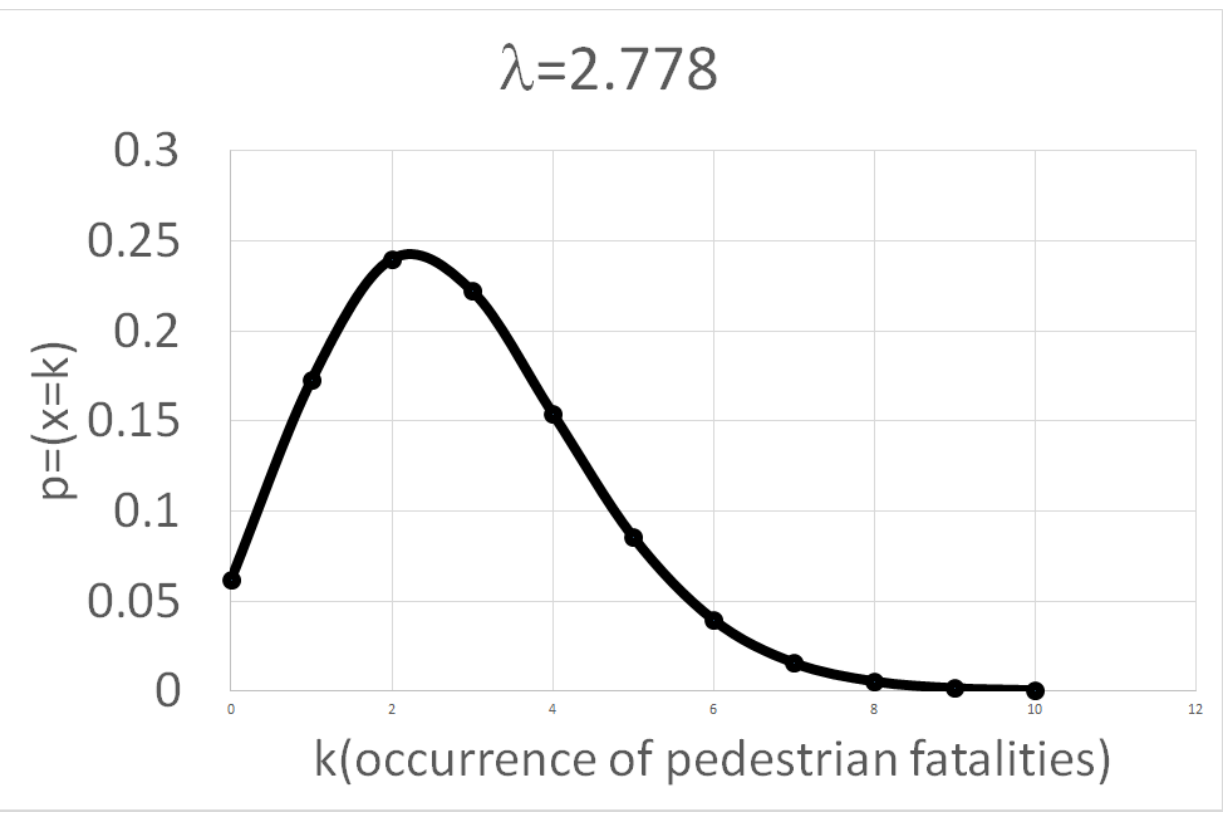

Figure 3. Poisson probability distribution for pedestrian fatalities in Jeddah.

GWR models use a spatial kernel to weight parameter estimates over a geographical space. The proper kernel type should be chosen before the calibration of the GWR model. Usually, there are two kinds of kernels, i.e., fixed and adaptive. We used the adaptive kernel type, which is most suitable in case of spatial clustering [47]. To compare the GWR models, Akaike Information Criterion (AICc) is a common measure for the "goodness of fit", and to make comparison between different models [61]. A model with a lower AICc value shows the excellent performing model because of the best goodness of fit among all tested models [47].

\section{Results}

5.1. Moran I and LISA Clusters for Pedestrian Fatalities

At first, the data show that two districts of Jeddah, namely Al Rabbwah and Meshrefah, are the home of more than one-third of the total pedestrian fatalities in the reported year (Table 6).

Table 6. Top 10 districts in pedestrian fatalities.

\begin{tabular}{ccc}
\hline Name of the District & No. of Pedestrian Fatalities & Rank \\
\hline Al Rabbwah & 62 & 1 \\
Meshrefah & 43 & 2 \\
Al Ruwase & 24 & 3 \\
Al Azizeyyah & 16 & 4 \\
Al Safa & 15 & 5 \\
Al Jameaah & 13 & 6 \\
Al Faysaleyyah & 12 & 7 \\
Al Zahrah & 12 & 7 \\
Al Sharafeyyah & 12 & 7 \\
Al Thagur & 10 & 8 \\
Al Muhammadiyah & 9 & 9 \\
Al Rehab & 8 & 10 \\
Al Hendaweyyah & 8 & 10 \\
\hline
\end{tabular}


It is apparent from the above table that spatial clustering of pedestrian fatalities in probable in Jeddah. The results of Moran's I univariate statistic confirm that pedestrian fatalities in Jeddah are spatially clustered (Figure 4). The results of LISA also confirm that the pedestrian fatalities in Jeddah are geographically clustered with varying levels of significance based on the application of both univariate and multivariate spatial econometric statistics.

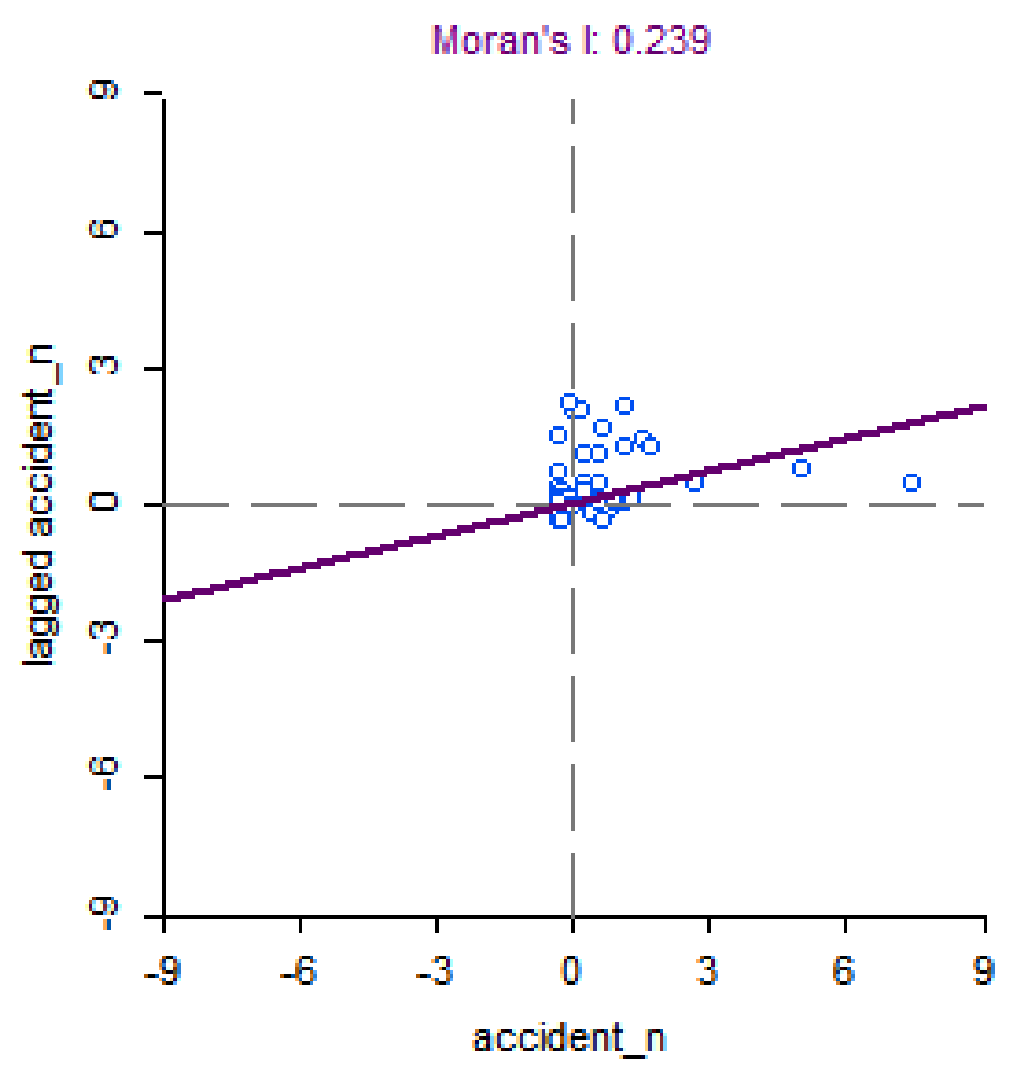

Figure 4. Moran's, I scatter plot for the pedestrian fatalities in Jeddah.

Moran's index for the pedestrian fatalities in Jeddah gives a value of 0.239 , which is significant because the $z$ score for the value is $4.3673(<2.58)$ at $p=0.001$; some earlier studies [62] demonstrate that the $z$ score is a useful guide to determine the significance of Moran's I; if the z score is positive and beyond the critical value, it suggests spatial clustering of the variable and vice versa.

As mentioned above, we used LISA detect local spatial autocorrelation for the districtwise pedestrian fatalities clustering in Jeddah (Figure 5). LISA helped us differentiate the locations that are contributing to global Moran's I in a strong manner through clustering maps; LISA cluster maps can also probe into the direction of spatial association [63]. Results of the LISA cluster map showed that pedestrian fatalities are not significant in 101 districts out of a total of 113 districts. However, the clustering of pedestrian fatalities was seen in nine districts (high-high clustering) that are in the north and northeast direction of the old city center (Al-Balad). 


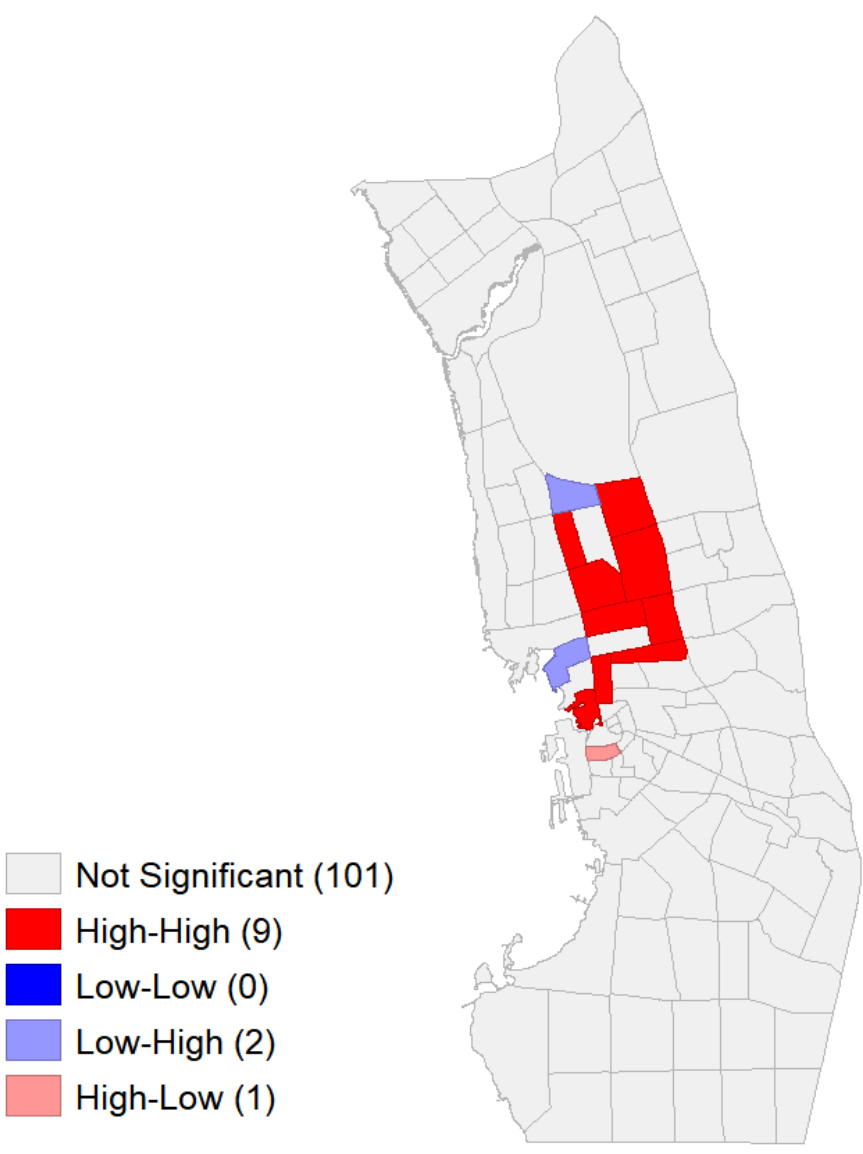

Figure 5. Local Indicators of Spatial Association (LISA) cluster map for pedestrian fatalities in Jeddah.

\subsection{Model}

As mentioned earlier in the method section, we developed global regression and GWR (geographically weighted regression) models with Poisson distribution and offer the presented the results in Table 7.

Table 7. Global regression and GWR (geographically weighted regression) results.

\begin{tabular}{|c|c|c|c|c|c|c|c|c|}
\hline \multirow{3}{*}{ Variable } & \multicolumn{7}{|c|}{ Model Type: Poisson } & \\
\hline & \multicolumn{4}{|c|}{ Global Regression } & \multicolumn{4}{|c|}{ GWR } \\
\hline & Estimate & SE & $t$ Value & Exp (Est) & Min & Max & Mean & Std Dev \\
\hline Intercept & 0.552697 & 0.075392 & 7.331022 & 1.737934 & -2.924530 & 1.876454 & 0.034356 & 1.178538 \\
\hline Land use & -0.200133 & 0.075751 & -2.641966 & 0.818622 & -0.373459 & 0.771673 & 0.029784 & 0.324133 \\
\hline $\begin{array}{c}\text { Transport infrastructure } \\
\text { Diagnostic }\end{array}$ & 0.919403 & 0.049403 & 18.610388 & 2.507794 & 0.315160 & 3.183010 & 1.422845 & 0.930003 \\
\hline \% deviance explained & & & & 0.344184 & & & & 0.625215 \\
\hline AICc & & & & 745.446913 & & & & 442.968 \\
\hline
\end{tabular}

The results of the model show that GWR functioned better than the global regression. The corrected Akaike information criterion (AICc) value for GWR is lower than the global regression, and a comparatively higher percentage of explained deviance confirms the performance of GWR model. Both scores are used for model validation. AICc is a single number score that is considered to find which model is most likely to be the best model (maximum likelihood estimation or log-likelihood) for a given dataset, while on other hand, the percentage of explained deviance is an analogue of $\mathrm{R}^{2}$ that informs on the goodness of fit of a model. 
The "land-use" factor is not significant for the global regression model having a negative sign, and it is significant for $26.36 \%$ of districts in GWR, based on local $t$-scores (Figure 6). The coefficient for this factor is moderate and self-explanatory; higher commercial, residential, school, and hospital density makes drivers and pedestrians cautious, leading to less pedestrian fatalities. However, the contribution of this factor in the global model is minimal, which is clear by the lower estimate value of -0.200133 (Table 7). Additionally, the old city center (Al-Balad) has a higher commercial and residential density; however, pedestrian fatalities have been negligible in the district because of driving restrictions during peak business hours.
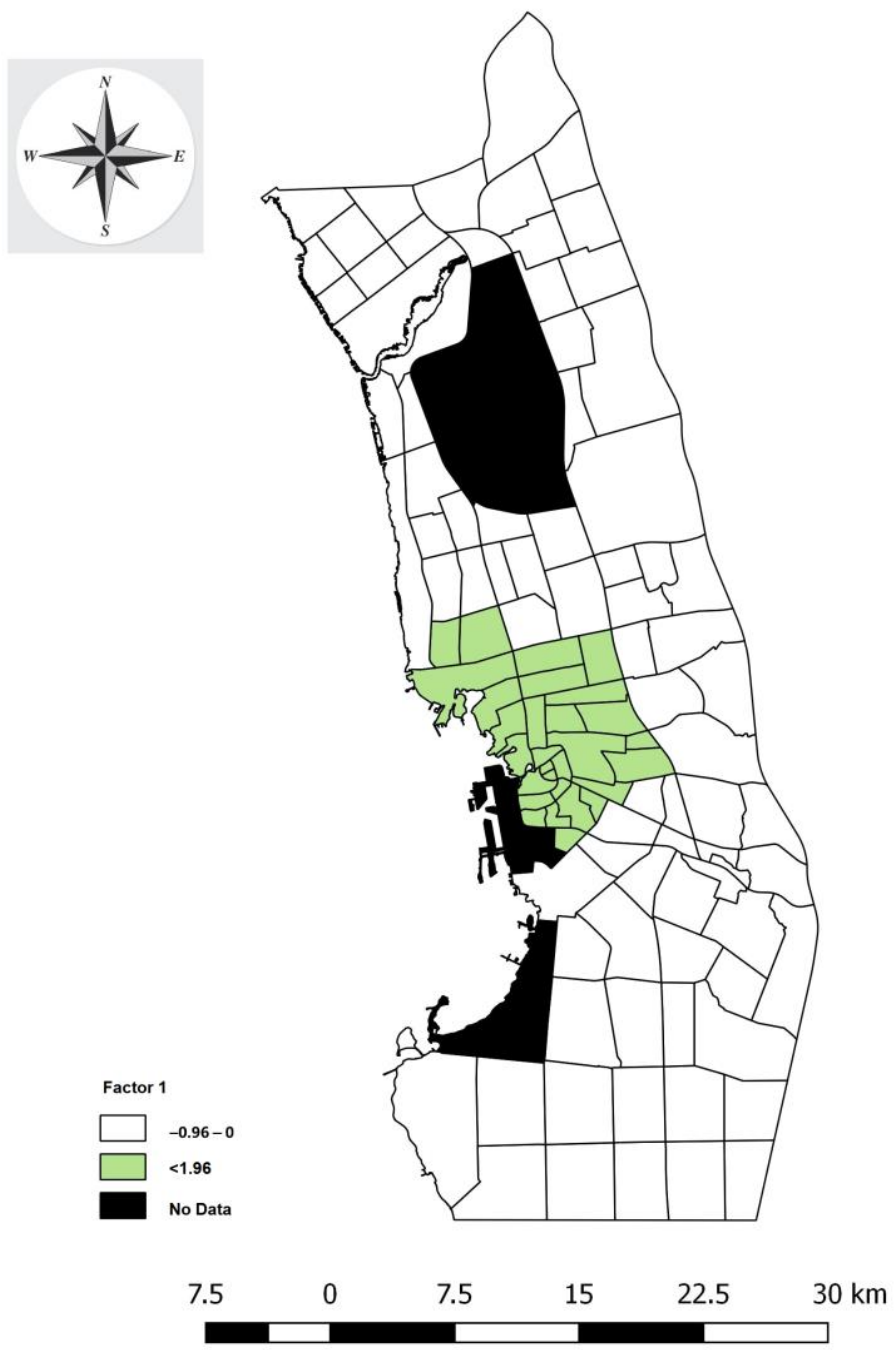

Figure 6. Local t-scores: higher land-use density associated with less risk of pedestrian fatalities.

The "transport infrastructure" factor is significant for the global regression model having a positive sign, and it is significant for $77.27 \%$ districts in GWR on the basis of local $t$-scores (Figure 7). The coefficient for this factor is highest at the global level. It is reflected into a higher coefficient value in the global model, which is 0.919403 (Table 6). The global model prompts that the existing transport infrastructure in the city is unsafe, leading to more pedestrian fatalities provided that the modal share of pedestrians is as low as $9 \%$. 


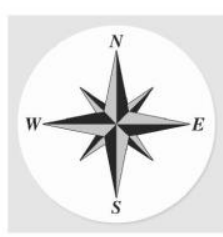

Factor 2
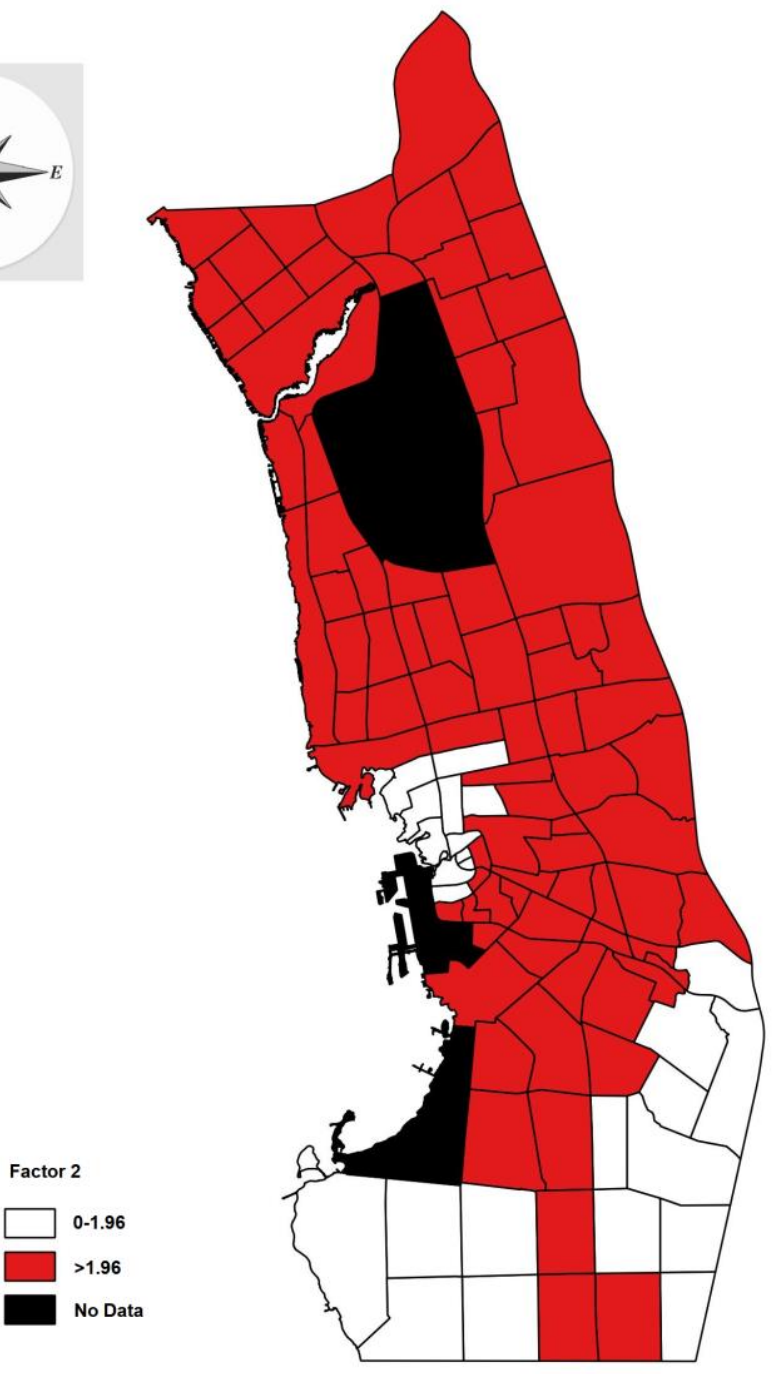

7.5 0

$7.5 \quad 15$

22.5

$30 \mathrm{~km}$

Figure 7. Local t-scores: higher density of transportation infrastructure associate with more risk of pedestrian fatality.

\section{Discussion}

At first, the modal share of public transport trips in Jeddah is just 2.3\%; perhaps this is the reason of movement of 5.2 million vehicles and 167,000 trips daily. The road volume-capacity ratio is comparatively higher in the districts where pedestrian fatalities are spatially clustered. It reveals that the handling of large traffic volume is beyond the capacity of the existing road network in certain districts of the city. Obviously, expansion in the road network is not a sustainable solution to this challenge because every growth has its limit [64]. Expansion in public transport coverage and encouraging people to use public transport often may reduce the usual congestion of private vehicles over the city road network.

Secondly, Jeddah has a model share of pedestrians as low as $9 \%$. The visual observation of pedestrian infrastructure across the city reveals that a continuous pedestrian network is absent even at the locations where the pedestrian volume is much higher. Recently, city authorities have started to expand pedestrian networks, although the expansion is not sufficiently covering most of the medium to high-density districts. Pedestrian pathways are not separated from the traffic lane, which increases the risk of pedestrian 
fatality. We feel that foot overbridges are not popular among pedestrians because of the increased time and effort required to cross the roads through foot overbridges; also, foot overbridges are covering a tiny part of the main road network in the city. Hence, we recommend the provision of integrated, connected, safe, comfortable, and clearly marked pedestrian infrastructure across the city. It should also amalgamate sufficient coverage of foot overbridges equipped with automatic elevators and thermal comfort.

Thirdly, the results of the study show that the pedestrian fatalities are clustered at the medium to high-density districts i.e., Al Rabbwah, Meshrefah, and Al Ruwase (Figure 5). It is worth mentioning that a significant part of these districts fall under unplanned area, and the re-development projects in these areas are either in progress or anticipated. That is why it is a good time to integrate and implement traffic safety-related measures in these areas.

Fourthly, the GWR model shows that transport infrastructure is a significant factor contributing to pedestrian fatalities (Table 6 and Figure 6). Better provision of road network, road volume capacity ratio, road intersection density, and traffic signal densities are part and parcel of transport infrastructure in varying loadings. The volume-capacity ratio is contributing positively to pedestrian fatalities, which is dissimilar to the results of a previous study in Detroit [44]. A higher volume-capacity ratio is surely an outcome of a huge number of vehicles in the city, which could be regulated by limiting number of vehicles per household (under consideration with the government) and adequate provision of public transportation amenities. In addition, the design and safety at the intersection should be increased after comprehensive audits.

Fifth, the model also confirms a negative association of pedestrian fatalities with the land-use factor (Table 6 and Figure 7), which is inclusive of population densities that reinforce findings of an earlier study on Delhi that concludes that populated land uses lead to less pedestrian fatalities [42]. However, our results are obtained in a different context, where the modal share of pedestrians is less than half in comparison to Delhi (Table 1). A smaller modal share of pedestrians in Jeddah is perhaps due to the hot climate; hence, enabling thermal comfort might increase the model share of pedestrians, especially in the dense and traffic generating areas, leading to a smaller number of pedestrian fatalities.

Sixth, a location-specific study matters a lot while making policies on traffic safety. The contribution of this study is to propose a geographically weighted Poisson regression model by which transport planners and policy makers can better understand the locational heterogeneity of road traffic fatalities. They can also perceive how these traffic fatalities are dispersed all over the city by which they can formulate a location-specific strategic plan for the pedestrian safety in each district.

Other studies have modelled the association of pedestrian fatalities in the context of mixed traffic $[19,65]$. However, the contribution of this study is that we have modelled the relationship of pedestrian fatalities associated with several urban variables in context to a car-dominated city such as Jeddah, where the model share of pedestrians and public transport users is lowest. We simplified and minimized ten urban variables into two consistent and strong factors. However, this study has some limitations; for instance, the behaviours of pedestrians and drivers' socio-technical advances (use of smartphones while driving) are not included in the modeling due to an absence of data. The limitations of this study might be overcome in future studies through extensive and added recurring data connected to pedestrian fatalities.

\section{Conclusions}

In this paper, we attempted to explore the geographically varying association between the pedestrian fatalities and other associated urban environment factors in Jeddah city using Moran's I, LISA. and geographically weighted Poisson regression methods. Moran's I and LISA results (Figure 5) indicate the clustering of pedestrian fatalities in the certain districts of Jeddah. Additionally, GWRP results demonstrate that the transportation infrastructure in Jeddah was significantly associated with the higher pedestrian fatalities. In addition, a higher number of vehicles per household and high volume-capacity ratio 
is problematic; hence, limiting the number of private vehicles and adequate provision of public transportation is suggested. We also recommend that a connected and convenient pedestrian network can substantially lower the fatalities among pedestrians, which reinforces the findings from some earlier research on this topic $[8,26]$. In doing so, the thermal comfort for pedestrians should be addressed. Although the study provides a sophisticated approach that facilitates the analysis and improvement of road safety for pedestrians in car-dependent cities, we recommend the consideration of the pedestrians and drivers behaviour in the context of recent socio-technical advances. Hence, further studies are recommended with extended data on pedestrian fatalities through nascent machine learning (ML) approaches [66].

Author Contributions: Both authors equally contributed for the work. All authors have read and agreed to the published version of the manuscript.

Funding: This project was funded by the Deanship of Scientific Research (DSR), King Abdulaziz University, Jeddah, under grant No. (DF-829-137-1441). The author, therefore, gratefully acknowledge DSR technical and financial support.

Institutional Review Board Statement: Not Applicable.

Informed Consent Statement: Not Applicable.

Data Availability Statement: Not Applicable.

Conflicts of Interest: The authors declare no conflict of interest.

\section{References}

1. World Health Organization (WHO). Global Status Report on Road; World Health Organization: Geneva, Switzerland, 2018 ; p. 20.

2. Chinnappa Nanjunda, D. Impact of socio-economic profiles on public health crisis of road traffic accidents: A qualitative study from South India. Clin. Epidemiol. Glob. Health 2020. [CrossRef]

3. Kovačević, J.; Miškulin, M.; Ličanin, M.M.; Barać, J.; Biuk, D.; Palenkić, H.; Matić, S.; Kristić, M.; Biuk, E.; Miškulin, I. Quality of life in road traffic accident survivors. Slov. J. Public Health 2020, 59, 202-210. [CrossRef]

4. Chen, S.; Kuhn, M.; Prettner, K.; Bloom, D.E. The global macroeconomic burden of road injuries: Estimates and projections for 166 countries. Lancet Planet. Health 2019, 3, e390-e398. [CrossRef]

5. Jones, S.; Odero, K.; Adanu, E.K. Road crashes in Namibia: Challenges and opportunities for sustainable development. Dev. South. Afr. 2020, 37, 295-311. [CrossRef]

6. Naci, H.; Chisholm, D.; Baker, T.D. Distribution of road traffic deaths by road user group: A global comparison. Inj. Prev. 2009, 15, 55-59. [CrossRef]

7. Mansfield, T.J.; Peck, D.; Morgan, D.; McCann, B.; Teicher, P. The effects of roadway and built environment characteristics on pedestrian fatality risk: A national assessment at the neighborhood scale. Accid. Anal. Prev. 2018, 121, 166-176. [CrossRef]

8. Nesoff, E.D.; Milam, A.J.; Pollack, K.M.; Curriero, F.C.; Bowie, J.V.; Gielen, A.C.; Furr-Holden, D.M. Novel Methods for Environmental Assessment of Pedestrian Injury: Creation and Validation of the Inventory for Pedestrian Safety Infrastructure. J. Urban Health 2018, 95, 208-221. [CrossRef] [PubMed]

9. Martin, J.-L.; Wu, D. Pedestrian fatality and impact speed squared: Cloglog modeling from French national data. Traffic Inj. Prev. 2018, 19, 94-101. [CrossRef] [PubMed]

10. Hussain, Q.; Feng, H.; Grzebieta, R.; Brijs, T.; Olivier, J. The relationship between impact speed and the probability of pedestrian fatality during a vehicle-pedestrian crash: A systematic review and meta-analysis. Accid. Anal. Prev. 2019, 129, 241-249. [CrossRef]

11. Thomas, M.; Riemann, B.; Jones, J. Epidemiology of alcohol and drug screening among pedestrian fatalities in the United States, 2014-2016. Traffic Inj. Prev. 2019, 20, 557-562. [CrossRef] [PubMed]

12. Das, S.; Ashraf, S.; Dutta, A.; Tran, L.-N. Pedestrians under influence (PUI) crashes: Patterns from correspondence regression analysis. J. Saf. Res. 2020. [CrossRef]

13. Kraidi, R.; Evdorides, H. Pedestrian safety models for urban environments with high roadside activities. Saf. Sci. 2020, 130, 104847. [CrossRef]

14. Budzynski, M.; Jamroz, K.; Mackun, T. Pedestrian Safety in Road Traffic in Poland. IOP Conf. Ser. Mater. Sci. Eng. 2017, 245, 042064. [CrossRef]

15. Sarwar, M.T.; Fountas, G.; Bentley, C.; Anastasopoulos, P.C.; Blatt, A.; Pierowicz, J.; Majka, K.; Limoges, R. Preliminary Investigation of the Effectiveness of High-Visibility Crosswalks on Pedestrian Safety Using Crash Surrogates. Transp. Res. Rec. J. Transp. Res. Board 2017, 2659, 182-191. [CrossRef]

16. Wood, J.M. Nighttime driving: Visual, lighting and visibility challenges. Ophthalmic Physiol. Opt. 2020, 40, 187-201. [CrossRef] [PubMed] 
17. Kim, D. The transportation safety of elderly pedestrians: Modeling contributing factors to elderly pedestrian collisions. Accid. Anal. Prev. 2019, 131, 268-274. [CrossRef] [PubMed]

18. Ferenchak, N.N.; Marshall, W.E. Redefining the child pedestrian safety paradigm: Identifying high fatality concentrations in urban areas. Inj. Prev. 2017, 23, 364-369. [CrossRef]

19. Lakhotia, S.; Lassarre, S.; Rao, K.R.; Tiwari, G. Pedestrian accessibility and safety around bus stops in Delhi. IATSS Res. 2020, 44, 55-66. [CrossRef]

20. Craig, C.M.; Morris, N.L.; Van Houten, R.; Mayou, D. Pedestrian Safety and Driver Yielding Near Public Transit Stops. Transp. Res. Rec. J. Transp. Res. Board 2019, 2673, 514-523. [CrossRef]

21. Mukherjee, D.; Mitra, S. Impact of Road Infrastructure Land Use and Traffic Operational Characteristics on Pedestrian Fatality Risk: A Case Study of Kolkata, India. Transp. Dev. Econ. 2019, 5, 6. [CrossRef]

22. Dai, D.; Jaworski, D. Influence of built environment on pedestrian crashes: A network-based GIS analysis. Appl. Geogr. 2016, 73, 53-61. [CrossRef]

23. Combs, T.S.; Sandt, L.S.; Clamann, M.P.; McDonald, N.C. Automated Vehicles and Pedestrian Safety: Exploring the Promise and Limits of Pedestrian Detection. Am. J. Prev. Med. 2019, 56, 1-7. [CrossRef]

24. Simmons, S.M.; Caird, J.K.; Ta, A.; Sterzer, F.; Hagel, B.E. Plight of the distracted pedestrian: A research synthesis and metaanalysis of mobile phone use on crossing behaviour. Inj. Prev. 2020, 26, 170-176. [CrossRef] [PubMed]

25. Piazza, A.J.; Knowlden, A.P.; Hibberd, E.; Leeper, J.; Paschal, A.M.; Usdan, S. Mobile device use while crossing the street: Utilizing the theory of planned behavior. Accid. Anal. Prev. 2019, 127, 9-18. [CrossRef] [PubMed]

26. Khatoon, M.; Tiwari, G.; Chatterjee, N. Impact of grade separator on pedestrian risk taking behavior. Accid. Anal. Prev. 2013, 50, 861-870. [CrossRef]

27. Nasar, J.L.; Troyer, D. Pedestrian injuries due to mobile phone use in public places. Accid. Anal. Prev. 2013, 57, 91-95. [CrossRef] [PubMed]

28. Al Turki, Y.A. How can Saudi Arabia use the Decade of Action for Road Safety to catalyse road traffic injury prevention policy and interventions? Int. J. Inj. Contr. Saf. Promot. 2014, 21, 397-402. [CrossRef] [PubMed]

29. Ansari, S.; Akhdar, F.; Mandoorah, M.; Moutaery, K. Causes and effects of road traffic accidents in Saudi Arabia. Public Health 2000, 114, 37-39. [CrossRef]

30. Hegazy, I.R.; Qurnfulah, E.M. Thermal comfort of urban spaces using simulation tools exploring street orientation influence of on the outdoor thermal comfort: A case study of Jeddah, Saudi Arabia. Int. J. Low-Carbon Technol. 2020. [CrossRef]

31. Masoud, B.; Coch, H.; Beckers, B. The Correlation Between Urban Morphology Parameters and Incident Solar Radiation Performance to Enhance Pedestrian Comfort, Case Study Jeddah, Saudi Arabia. In Sustainability in Energy and Buildings; Springer: Singapore, 2020; pp. 543-554.

32. Daghestani, A.M. A Case Study in Planning Implementation; Working paper no. 32; University of Newcastle 703 upon Tyne: Newcastle upon Tyne, UK, 1993.

33. Aljoufie, M. Toward integrated land use and transport planning in fast-growing cities: The case of Jeddah, Saudi Arabia. Habitat Int. 2014, 41, 205-215. [CrossRef]

34. Jeddah Municipality Transportation and Traffic Development Plan; Jeddah Municipality: Jeddah, Saudi Arabia, 2006.

35. Aljoufie, M.; Zuidgeest, M.; Brussel, M.; van Maarseveen, M. Spatial-temporal analysis of urban growth and transportation in Jeddah City, Saudi Arabia. Cities 2013, 31, 57-68. [CrossRef]

36. Ministry of Transport. Ministry of Transport KSA Report of Traffic Monitoring Unit; Ministry of Transport: Riyadh, Saudi Arabia, 2019.

37. Government of Saudi Arabia. Kingdom of Saudi Arabia Vision 2030; Government of Saudi Arabia: Riyadh, Saudi Arabia, 2016.

38. Frank, L.D. Land Use and Transportation Interaction. J. Plan. Educ. Res. 2000, 20, 6-22. [CrossRef]

39. Kaygisiz, Ö.; Senbil, M.; Yildiz, A. Influence of urban built environment on traffic accidents: The case of Eskisehir (Turkey). Case Stud. Transp. Policy 2017, 5, 306-313. [CrossRef]

40. Kmet, L.; Macarthur, C. Urban-rural differences in motor vehicle crash fatality and hospitalization rates among children and youth. Accid. Anal. Prev. 2006, 38, 122-127. [CrossRef]

41. Zwerling, C. Fatal motor vehicle crashes in rural and urban areas: Decomposing rates into contributing factors. Inj. Prev. 2005, 11, 24-28. [CrossRef]

42. Ewing, R.; Schieber, R.A.; Zegeer, C.V. Urban Sprawl as a Risk Factor in Motor Vehicle Occupant and Pedestrian Fatalities. Am. J. Public Health 2003, 93, 1541-1545. [CrossRef]

43. Golob, T.F.; Recker, W.W. Relationships Among Urban Freeway Accidents, Traffic Flow, Weather, and Lighting Conditions. J. Transp. Eng. 2003, 129, 342-353. [CrossRef]

44. Zhou, M.; Sisiopiku, V.P. Relationship Between Volume-to-Capacity Ratios and Accident Rates. Transp. Res. Rec. J. Transp. Res. Board 1997, 1581, 47-52. [CrossRef]

45. Vorko-Jović, A.; Kern, J.; Biloglav, Z. Risk factors in urban road traffic accidents. J. Saf. Res. 2006, 37, 93-98. [CrossRef]

46. Chen, A.C.; Moran, S.; Sun, Y.; Vu, K.-P.L. Comparison of Intellectus Statistics and Statistical Package for the Social Sciences. In Engineering Psychology and Cognitive Ergonomics; Springer: Berlin/Heidelberg, Germany, 2018; pp. 389-402.

47. Grekousis, G. Multivariate Data in Geography. In Spatial Analysis Methods and Practice; Cambridge University Press: Cambridge, UK, 2020; pp. 275-350. 
48. Costello, A.B.; Osborne, J.W. Best practices in exploratory factor analysis: Four recommendations for getting the most from your analysis. Pract. Assess. Res. Eval. 2005, 10,7.

49. Braeken, J.; van Assen, M.A.L.M. An empirical Kaiser criterion. Psychol. Methods 2017, 22, 450-466. [CrossRef] [PubMed]

50. Jackson, J.E. Oblimin Rotation. In Encyclopedia of Biostatistics; John Wiley \& Sons, Ltd: Chichester, UK, 2005.

51. Tabachnick, B.G.; Fidell, L.S. Using Multivariate Statistics, 14th ed.; Pearson Education: New York, NY, USA, 2019.

52. Field, A. Discovering Statistics Using IBM SPSS Statistics, 4th ed.; Sage: Thousand Oaks, CA, USA, 2017.

53. Yong, A.G.; Pearce, S. A Beginner's Guide to Factor Analysis: Focusing on Exploratory Factor Analysis. Tutor. Quant. Methods Psychol. 2013, 9, 79-94. [CrossRef]

54. Floyd, F.J.; Widaman, K.F. Factor analysis in the development and refinement of clinical assessment instruments. Psychol. Assess. 1995, 7, 286-299. [CrossRef]

55. Comrey, A.L. A First Course in Factor Analysis; Psychology Press: New York, USA, 2013; ISBN 9781315827506.

56. Moran, P.A.P. The Interpretation of Statistical Maps. J. R. Stat. Soc. Ser. B 1948, 10, 243-251. [CrossRef]

57. Pereira, R.H.M.; Nadalin, V.; Monasterio, L.; Albuquerque, P.H.M. Urban Centrality: A Simple Index. Geogr. Anal. 2013, 45, 77-89. [CrossRef]

58. Anselin, L. Local Indicators of Spatial Association-LISA. Geogr. Anal. 2010, 27, 93-115. [CrossRef]

59. Tang, J.; Gao, F.; Liu, F.; Han, C.; Lee, J. Spatial heterogeneity analysis of macro-level crashes using geographically weighted Poisson quantile regression. Accid. Anal. Prev. 2020, 148, 105833. [CrossRef]

60. Fotheringham, A.; Stewart, C.B.; Charlton, M. Geographically Weighted Regression: The Analysis of Spatially Varying Relationships; Wiley: West Sussex, UK, 2003.

61. Cavanaugh, J.E.; Neath, A.A. The Akaike information criterion: Background, derivation, properties, application, interpretation, and refinements. Wiley Interdiscip. Rev. Comput. Stat. 2019, 11, e1460. [CrossRef]

62. Siddiqui, C.; Abdel-Aty, M.; Choi, K. Macroscopic spatial analysis of pedestrian and bicycle crashes. Accid. Anal. Prev. 2012, 45, 382-391. [CrossRef]

63. Aljoufie, M.; Tiwari, A. Exploring Housing and Transportation Affordability in Jeddah. Hous. Policy Debate 2020, 1-27. [CrossRef]

64. Meadows, D.H.; Meadows, D.L.; Randers, J.; Behrens, W.W. Limits to Growth, 5th ed.; Routledge: New York, NY, USA, 1972.

65. Rosén, E.; Stigson, H.; Sander, U. Literature review of pedestrian fatality risk as a function of car impact speed. Accid. Anal. Prev. 2011, 43, 25-33. [CrossRef] [PubMed]

66. Ghandour, A.J.; Hammoud, H.; Al-Hajj, S. Analyzing Factors Associated with Fatal Road Crashes: A Machine Learning Approach. Int. J. Environ. Res. Public Health 2020, 17, 4111. [CrossRef] [PubMed] 